\title{
Becoming a culturally competent nurse
}

\author{
Valarie F. Thomas \\ Miller Hall, Auburn University, Auburn, USA \\ Email: vzt0009@auburn.edu \\ Received 15 October 2013; revised 19 November 2013; accepted 12 December 2013 \\ Copyright (C) 2013 Valarie F. Thomas. This is an open access article distributed under the Creative Commons Attribution License, \\ which permits unrestricted use, distribution, and reproduction in any medium, provided the original work is properly cited.
}

\begin{abstract}
Cultural competence in nursing provides an ideal avenue to meet the various needs of our patients while providing them with safe, competent care. "Racial and ethnic differences in family expectations or preferences for care are not yet well identified and cataloged, but they may uniquely affect individual ratings or experience with care" [1]. The purpose of this article is to enlighten nurses as health care providers about cultural care in an effort to provide that safe, competent care. Many times patients present for care at hospitals and clinics with language barriers and preconceived ideas based on their own cultural beliefs and practices. It is ideal when we, as nurses have the ability to meet those needs in an effort to meet patient's expectations and healthcare needs. In order to meet the diverse needs of our growing multi-cultural population, it is becoming apparent that we must not only provide care based on the physical needs, but the entire person's needs relevant to their cultural beliefs regarding healthcare practices and the healing process.
\end{abstract}

Keywords: Safe Nursing Care; Nursing Care Needs; Quality Nursing Care; Provide Nursing Care; Quality Patient Care

\section{INTRODUCTION}

Cultural competence and the delivery of healthcare are an ongoing process that allows the nurse to constantly strive to obtain the ability to become an effective nurse in the area of cultural care as we provide services to our patients, the family, and the community [2]. As nurses, we have been exposed to the phrase "holistic approach to nursing” probably since nursing school and throughout our professional career. What does this mean? It means as nurses caring for others, that we are to consider each of our patients as a whole person in order to provide the most efficient, safe nursing care. Thereby, we meet or consider what other needs our patients may have in addition to their current diagnosis. We consider patients' physiological, spiritual, psychological, and social needs while ignoring oftentimes their cultural needs as an essential process of healing. As nurses, we will at some point in our professional careers deal with patients that are different from ourselves and our own beliefs and practices. The key to becoming a culturally competent nurse is to understand that all patients are not the same and should be viewed as unique individuals.

The purpose of this article is to enlighten us as caregivers that there is a need to incorporate culturally appropriate interventions in our model of holistic care into allow those individuals entrusted to us to be fully restored to a state of health. We have the responsibility to promote health and healing, prevent illness and disease, and minimize the distress of the critically ill and dying. As stated by the American Nurses Association (ANA) Code of Ethics "the nurse promotes, advocates for and strives to protect the health, safety and rights of the patient” [3]. A portion of how we do this is to first educate ourselves as we attempt to educate others.

\section{VALUABLE EXPERIENCES}

As a nurse providing care for clients of several cultures and nationalities, it was often difficult to view the patients' side of the story. I want to care for them using the same approach I used for all the others I had cared for with the same illnesses and issues. It made sense to me to provide nursing care in the same way. Treatment options are really the same for one and all correct? Not necessarily so. How a person heals may solely depend on the treatment received and how the person views that particular treatment. For instance, think of this patient. A 32-year-old female Hispanic patient in an ICU setting, who has been admitted for sepsis, is critically ill, and is on a ventilator for several days. She has multiple family members that are now flooding the waiting room and one or maybe several of them desire to remain at the patient's bedside at all times. Many of them have travelled from 
across the nation to be present. As the caregiver, how do you, as the nurse handle this situation? When you consider the needs of the patient, the family dynamics, and the hospital policy, it becomes increasingly difficult to answer this question. The truth of the matter is, how can you consider the needs and illicit the best outcome for the patient while adhering to the policies and procedures of the institution. This is where understanding the Hispanic culture will be valuable. Understanding the patient's culture allows us as nurses to deliver critical, complex nursing care needs for a given patient, family and community [4]. The care of this particular patient now involves not just the patient, but the family as well in order to promote optimum health and healing.

Now consider this patient. You, the nurse, are caring for a 48-year-old Jewish male who has been admitted to your hospital. He has been scheduled for several tests and his physician has ordered him to have nothing by mouth (NPO) until the tests are completed. His tests are not completed until 6:30 pm and the cafeteria is now closed for dinner meals. He has special diet orders for kosher meals only. When he returns from his tests, his diet is resumed and all you have on the unit as a possible meal for him is a ham or turkey sandwich and applesauce. What do you think will happen as he is a devout Jew that will not consider any other option for nutrition except kosher foods? As a result, he plans to fast for the night. Imagine being the nurse of this particular patient?

\section{CULTURALLY COMPETENT CARE}

It has been estimated that there were at least 13.3 million legal permanent residents living in the United States as of January 1, 2012. An estimated 8.8 million of the total 13.3 million were eligible to become US citizens [5]. In order to properly care for our patients we will have to ask ourselves and our patients a series of questions. These questions allow us as healthcare professionals to gain a better understanding of our patient's needs and how we may best meet those needs. It would be helpful to understand the patient's background with questions such as: how long have you been in the United States? What is your primary language spoken in the home? What is your religious preference? One of the greatest barriers that we face is linguistics when providing competent care. Healthcare institutions are required to have some form of language translation methods in place to effectively communicate with patients that do not have English as the primary language. The translators may be via phone devices used in healthcare facilities or actual translators for healthcare purposes. When we acquire the necessary tools to effectively communicate, we acquire a large portion of the ability to create change that ultimately creates a more knowledgeable nurse/caregiver. According to the Joint Commission on Accreditation of Healthcare Or- ganizations (JCAHO), hospitals are now implementing ways to address existing language barriers. These institutions are developing policies and procedures to ensure every patient and healthcare worker have available resources to obtain necessary knowledge from the patient in order to provide quality nursing care and quality care overall. JCAHO has made several efforts in the area of communication and requirements for hospitals and those providing care of patients, including nursing care, that every effort is made every to provide safe, competent, quality care. Despite these policies, many resources are underutilized [6].

The next step to becoming culturally competent is to value diversity and understanding that all patients are not the same. If we approach valuing diversity as learning opportunities, we find being more culturally competent more fulfilling. I have cared for many patients of different ages, racial backgrounds, nationalities, beliefs, and religions. Each experience has given me a more valuable look into what it is like to be different, respected, and valued. One of my best strategies in the area of gaining more knowledge about each culture is to simply "ask the patient”. Most people who are passionate about anything will answer questions in order to help us as the care givers understand what their culture is like, and beliefs of their culture. I have found this to help the patient to feel valued and respected. It allows me as the nurse to adapt to diverse and cultural needs as I provide nursing care.

Finally, each nurse should encourage social change within their institution. Ensuring necessary policies and procedures are enforced in the area of meeting the diverse needs of the patients, their families, and your colleagues, is one of the roadmaps to quality patient care and satisfaction. JCAHO interprets having the ability to provide effective communication, becoming culturally competent, and the inclusion of the patient and their family to be important in order to provide safe, quality care [7].

\section{SUMMARY}

Hospitals and healthcare organizations nationwide should consider their patients as individuals and seek to meet each patient needs on a patient by patient case. Without this view, patient care is at risk for negative outcomes and decreased satisfaction (Wilson-Stronks et al., 2010). It begins with not only the policy and procedures that have been implemented by the hospital, but also with the healthcare team honoring those policies and putting them into practice. As nurses become more aware of the diversity and needs of various cultures, it becomes necessary to create within ourselves the tools needed to ensure that every patient receives the highest quality care available. Knowledge of each patient's cultural needs for the healing process enhances the potential to create an 
environment of safety and satisfaction for patients, families, and within ourselves, while providing an essential aspect of holistic healing for the patient. To become more culturally competent is truly a dynamic learning experience.

\section{REFERENCES}

[1] Leiyu, S. and Stevens, G.D. (2010) Vunerable Populations in the United States. 2nd Edition, Jossey Bass San, Francisco,

[2] Campinha-Bacote, J. (2009) A culturally competent model of care for African-Americans. Urologic Nursing, 29, 49-54.

[3] Fowler, M. (2010) ANA guide to the code of ethics: In- terpretation and application. Nursebooks.org, Silver Spring, 143.

[4] Jarvis, C. (2012) Physical examination \& health assessment. 6th Edition, Elsevier Saunders, St. Louis.

[5] Rytina, N. (2013) Estimates of the Legal Permanent Resident Population in 2012. Office of Immigration Statistics, DHS, Washington, DC. www.dhs.gov/files/statistics/publications/LPR09.shtm

[6] Kupka, N., Tschurtz, B., Wilson-Stronks, A. and Galvez, E. (2010) The Joint Commission. 1-46. www.jointcommission.org

[7] Wilson-Stronks, A., Schyve and Rodriquez, I. (2010) Advancing effective communication, cultural competence, and patient- and family-centered competence. The Joint Commission, 1-102. www.jointcommision.org 